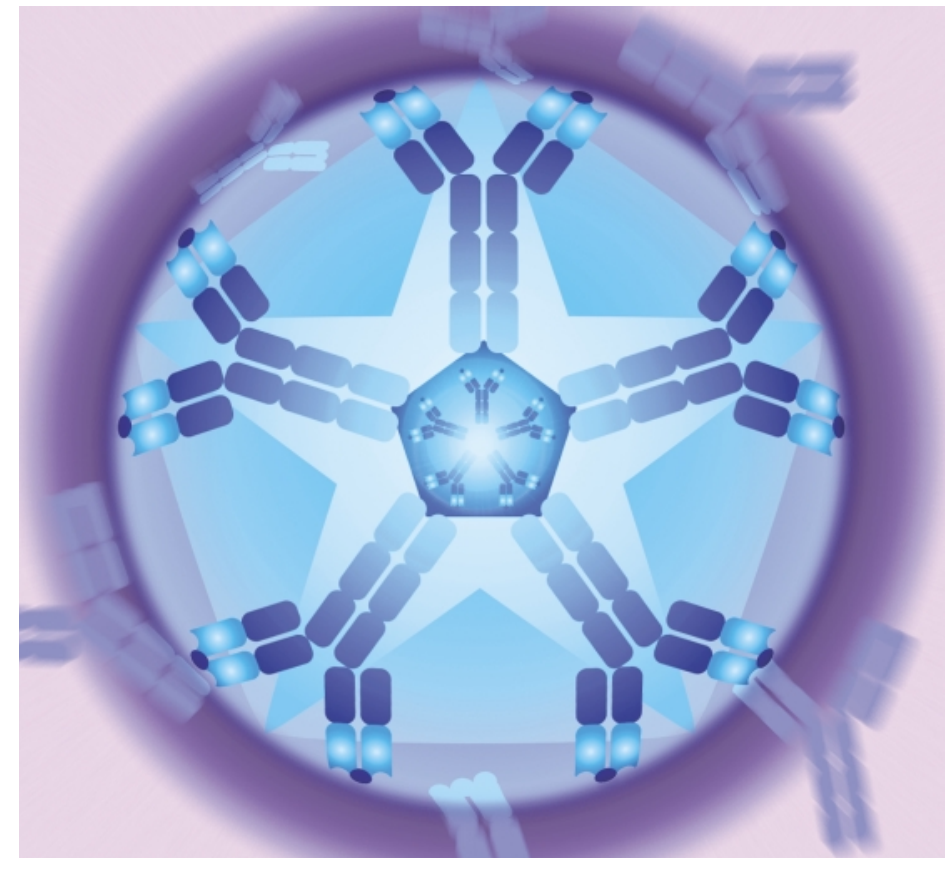

IMMUNOTHERAPY

\section{Friend or foe?}

The immune system seems to be a firm ally of prions. Not only do these infectious, modified proteins rely on the immune architecture for invasion and dispersal within their host, but also, immunological tolerance to the cellular version of the prion protein $\left(\mathrm{PrP}^{\mathrm{c}}\right)$ presents a formidable obstacle to vaccination against the antigenically indistinguishable disease-associated prion protein $\left(\mathrm{PrP}^{\mathrm{Sc}}\right)$. Heppner and colleagues now report, in Science, that antibodies to $\mathrm{PrP}$, produced in the host by a 'genetic trick', can protect against prion disease.

Scrapie infection in mice provides a useful model of prion diseases. In this study, a high-affinity, PrP-specific immunogolulin heavychain $\mathrm{V}$ region, derived from a PrPimmunized Prnp-deficient mouse, was used to create a transgenic mouse. The transgenic $\mu$-chain can pair with any of the endogenous light chains, resulting in a repertoire enriched in anti-PrP specificities of various affinities.

On a Prnp-deficient background, the transgenic mice spontaneously produce anti-PrP IgM antibodies, despite an absence of specific antigen. Transgenic mice on a Prnp-sufficient background also spontaneously produce anti-PrP antibody, but initially at lower levels and, crucially, there is no evidence of autoimmune disease.

But can these low levels of antiPrP antibodies protect against infection? To test this, transgenic Prnp $p^{+/ o}$ mice were innoculated with scrapie prions and protection was assessed in three ways. First, the abundance of prions in the spleen was measured by an in vivo bioassay, which showed a complete absence of infective prions. Second, western blots showed no trace of $\mathrm{PrP}^{\mathrm{sc}}$ in the spleens - normally a principal prion reservoir. Third, no scrapie deposits were found in the brains of these mice, indicating that prion transport to the central nervous system had been blocked.

Are the specific antibodies really responsible for this protection? An absence of follicular dendritic cells (FDCs), which depend on B cells for their development, is known to prevent scrapie pathogenesis. Could intrinsic immune defects in the transgenic mice account for their immunity to scrapie? The authors showed that the mice can produce normal levels of anti-viral antibody and also have normal clusters of FDCs in the spleen, implying that immune function is intact.

Importantly, this is the first indication that specific anti-PrP antibodies can protect against prion neuroinvasion. As no autoimmune disease occurred, passive transfer of anti-PrP immunity, either directly by antibodies or by gene therapy, might be a successful strategy against prion disease.

\section{(20) References and links} original RESEARCH PAPER Heppner, F. L. et al. Prevention of scrapie pathogenesis by transgenic expression of anti-prion protein antibodies. Science 6 September [e-pub ahead of print] (2001)

\section{WEB SITE}

Adriano Aguzzi's web site:

http://www.unizh.ch/pathol/neuropathologie/ ptn_aag_cv.html

\section{IN BRIEF}

\section{VACCINE DEVELOPMENT}

Recombinant viruses expressing a human malaria antigen can elicit potentially protective immune CD8 ${ }^{+}$ responses in mice.

Miyahira, Y. et al. Proc. Natl Acad. Sci. USA 95, 3954-3959 (2001)

The immunogenicity of vaccines depends on the regimen used. Miyahira et al describe total protection against malaria, in all mice injected with a replication-defective recombinant adenovirus expressing the circumsporozoite protein of Plasmodium yoelli, followed by a booster with an attenuated recombinant vaccinia virus expressing the same antigen. Long-lasting protection depended on the generation of memory $\mathrm{T}$ and $\mathrm{B}$ cells.

\section{INNATE IMMUNITY}

Inducible IL-2 production by dendritic cells revealed by global gene expression analysis.

Granucci, F. et al. Nature Immunol. 2, 882-888 (2001)

Immature dendritic cells (DCs) are specialized for antigen uptake but inflammatory signals induce their maturation into nonphagocytic cells capable of stimulating naive T-cell responses. Granucci et al. undertook a kinetic study of gene expression in DCs in response to bacterial stimulation and show that IL-2 is expressed by DCs, but not macrophages, as early as 4 hours after stimulation. These results help explain the unique T-cell stimulatory capacity of DCs.

\section{NEUROIMMUNOLOGY}

Infected splenic dendritic cells are sufficient for prion transmission to the CNS in mouse scrapie.

Aucouturier, P. et al. J. Clin. Invest. 108, 703-708 (2001)

Colonization of lymphoid tissues is an essential preliminary step in the prions' journey to the central nervous system. But how prions are transmitted from the immune system to the nervous system is unknown. Here, injection of dendritic cells (DCs) from scrapieinfected mice directly into the blood stream of $R a g 1^{-1-}$ mice, was sufficient to cause prion disease. It remains to be seen whether DCs are physiologically important players in prion neuroinvasion.

\section{AUTOIMMUNITY}

\section{A pathogenic role for myelin-specific $C D 80^{+} T$ cells in a} model for multiple sclerosis.

Huseby, E.S. et al. J Exp. Med. 194, 669-676 (2001)

$\mathrm{CD}^{+} \mathrm{T}$ cells have been the focus of research into multiple sclerosis, a disease characterized by autoimmune destruction of myelin. $\mathrm{CD}^{+} \mathrm{T}$ cells are also found at the scene of the crime; however, their role in pathogenesis has not been investigated. Myelin-basic-protein-specific $\mathrm{CD} 8^{+} \mathrm{T}$-cell clones were transferred into mice, causing a rapid neurological disease. The clinical signs and pathology differ from that seen in the more conventional experimental autoimmune encephaltis model, which is caused by $\mathrm{CD} 4^{+}$myelin-specific $\mathrm{T}$ cells. 